\title{
Drivers of macroinvertebrate community structure in unmodified streams
}

Often simple metrics are used to summarise complex patterns in stream benthic ecology, thus it is important to understand how well these metrics can explain the finer-scale underlying environmental variation often hidden by coarser-scale influences. I sampled 47 relatively pristine streams in the central North Island of New Zealand in 2007 and 1) evaluated the local-scale drivers of macroinvertebrate community structure as well as both diversity and biomonitoring metrics in this unmodified landscape, and 2) assessed whether these drivers were similar for commonly used univariate metrics and multivariate structure. The drivers of community metrics and multivariate structure were largely similar, with \% canopy cover and resource supply metrics the most commonly identified environmental drivers in these pristine streams. For an area with little to no anthropogenic influence, substantial variation was explained in the macroinvertebrate community (up to $70 \%$ on the first two components of a partial least squares regression), with both uni- and multivariate approaches. This research highlights two important points: 1) the importance of considering natural underlying environmental variation when assessing the response to coarse environmental gradients, and 2) the importance of considering canopy cover presence when assessing the impact of stressors on stream macroinvertebrate communities. 


\section{Drivers of macroinvertebrate community structure in unmodified streams}

2 Running head: Pristine stream macroinvertebrate communities

3 Jonathan D. Tonkin ${ }^{1,2}$

4 'Department of Environmental Science, Xi'an Jiaotong-Liverpool University, 111 Ren'ai Road,

5 Dushu Lake Higher Education Town, SIP, Suzhou, Jiangsu Province 215123, China

$6{ }^{2}$ Department of River Ecology and Conservation, Senckenberg Research Institute and Natural

7 History Museum, Clamecystrasse 12, Gelnhausen 63571, Germany

8 Telephone: +496051619543125

9 Email: jonathan.tonkin@senckenberg.de

\section{Abstract}

11 Often simple metrics are used to summarise complex patterns in stream benthic ecology, thus it is

12 important to understand how well these metrics can explain the finer-scale underlying

13 environmental variation often hidden by coarser-scale influences. I sampled 47 relatively pristine

14 streams in the central North Island of New Zealand in 2007 and 1) evaluated the local-scale drivers of macroinvertebrate community structure as well as both diversity and biomonitoring metrics in this unmodified landscape, and 2) assessed whether these drivers were similar for commonly used univariate metrics and multivariate structure. The drivers of community metrics and multivariate structure were largely similar, with \% canopy cover and resource supply metrics the most commonly identified environmental drivers in these pristine streams. For an area with little to no anthropogenic influence, substantial variation was explained in the macroinvertebrate community (up to $70 \%$ on the first two components of a partial least squares regression), with both uni- and multivariate approaches. This research highlights two important points: 1) the importance of considering natural underlying environmental variation when assessing the response to coarse environmental gradients, and 2) the importance of considering canopy cover presence when assessing the impact of stressors on stream macroinvertebrate communities.

26 Keywords: streams; macroinvertebrates; pristine; community structure; environmental variation;

27 lotic; freshwater; biomonitoring

\section{Introduction}


Streams are an important biodiversity reservoir within landscapes and benthic macroinvertebrates account for a large amount of this biodiversity. Many factors can influence stream macroinvertebrate diversity ranging from patch- to landscape-scale drivers (Vinson and Hawkins 1998, Heino 2009), including temperature and altitude (Jacobsen et al. 1997), disturbance (Death and Winterbourn 1995, Tonkin and Death 2012), and past (Harding et al. 1998) and current land use (Allan 2004). However, there is little consensus regarding any specific overriding influences on structure and diversity, but that they are a complex function of multiple environmental factors at multiple spatial and temporal scales (Poff 1997, Heino 2009). Catchment features generally exert influence on local-scale environmental features in stream systems (Johnson and Gage 1997, Johnson et al. 1997), just as regional species pools filter local macroinvertebrate colonisers (Poff 1997, Heino et al. 2003, Tonkin et al. 2014b). Yet, the importance of these larger-scale influences may be dependent on some form of human pressure such as land-use change being present (Heino et al. 2008), and often their influences are weak (Hawkins et al. 2000).

Both in biodiversity assessments and biomonitoring programs, these complex and diverse communities are often reduced to a single number to represent the entire community, such as a multitude of metrics representing species diversity (Magurran 2004), biotic integrity (e.g. Kerans and Karr, 1994), and the effects of organic enrichment (Stark 1985, Smith et al. 1999). However, metrics respond in different ways to environmental stressors (Yuan and Norton 2003). Thus the single-metric approach can overlook important information about the community and its response to stressors (Reynoldson et al. 1997, Collier 2009), highlighting the importance of using a variety of indices to indicate or represent the full range of environmental conditions. However, specific metrics may lack sensitivity to underlying variation in community structure resulting from other environmental conditions for which they were not designed. In essence, natural underlying environmental variation can obscure patterns along these stressor gradients. Other approaches, including multimetric, multivariate and predictive approaches (e.g. Clarke et al., 2003; Collier, 2009; Kerans and Karr, 1994), may thus be more appropriate.

One approach to assess the extent of this issue is to explore how well these metrics respond to environmental variation within pristine environments, where human stressors are largely absent. Previous studies have highlighted the importance of local-scale factors in shaping stream macroinvertebrate communities (Death and Joy 2004, Astorga et al. 2011). Accordingly, I aimed to 1) evaluate the local-scale drivers of macroinvertebrate community structure and diversity patterns in streams across a relatively unmodified landscape, and 2) assess whether these drivers were similar for commonly used univariate metrics and multivariate structure. To do 
62 this, I calculated several commonly applied univariate metrics, ranging from simple diversity indices to those developed for responding to organic enrichment (e.g. Macroinvertebrate

64 Community Index; MCI; Stark, 1985), and assessed the environmental factors explaining variation in these metrics and multivariate structure. Theoretically, community metrics should respond similarly to more complex multivariate analyses, but with variation in response depending on the metric's designed purpose. Therefore, I predicted that despite more variation being explained in the multivariate analyses, the main environmental influences would be similar for both univariate and multivariate approaches. Given the pristine nature of the streams sampled, I hypothesised the limited environmental gradients present would lead to low levels of variation explained.

\section{Material and methods}

\section{Study sites}

The Tongariro National Park in the central North Island of New Zealand comprises a central volcanic massif of three mountains of predominantly andesitic geology and the Tihia-kakaramea volcanic massif to the north. For sampling, 47 first- to sixth-order streams and rivers were selected from within the Tongariro National Park that were subjected to minimal human interference by excluding sites with greater than $10 \%$ catchment pastoral land use. All sites had a minimum of $90 \%$ volcanic hard sedimentary geology. Ten of the 47 sites had flows modified by hydroelectric dams, but as these were run-of-river type dams, they were not able to hold back floods and thus kept relatively natural flow regimes. The flow regimes of the remainder of sites were unmodified and ranged from runoff-fed streams to stable spring-fed streams. Eight sites were situated within Pinus radiata plantation forestry, but these sites were limited to mature forest, which has been found to have similar macroinvertebrate communities to native forest (Quinn et al. 1997, 2004). These sites belong to eight fifth order drainages (Fig. 1). For a more detailed description of the study sites, see Tonkin et al. (2013).

\section{Biological collections}

\section{Macroinvertebrates}

89 All sampling was performed on one occasion, between early February and late April 2007.

90 Macroinvertebrates were sampled by taking five $0.1-\mathrm{m}^{2}$ Surber samples $(250-\mu \mathrm{m}$ mesh, but later

91 sieved to $500 \mu \mathrm{m}$ ) from random locations from riffles throughout ca. 50 -m study reaches. 
92 Samples were preserved in $10 \%$ formalin before identification to the lowest possible taxonomic

93 level in the laboratory, using available keys (e.g. Towns and Peters, 1996; Winterbourn et al., 94 2000). Where certain taxa could not be identified to species level (e.g. Chironomidae and 95 Oligochaeta), I identified them to morphospecies. Several indices were calculated to summarise 96 different aspects of the macroinvertebrate community, ranging from diversity measures to 97 biomonitoring metrics developed as indicators of organic pollution. These are as follows: number 98 of individuals (density), number of taxa (richness), Macroinvertebrate Community Index (MCI) 99 (Stark 1985) and its quantitative variant the QMCI (Stark 1993), percent of Ephemeroptera, 100 Plecoptera and Trichoptera taxa (\%EPT taxa), percent of EPT individuals (\%EPT individuals), 101 the number of EPT taxa (EPT richness), and Margalef's diversity index (Clifford and Stephenson 102 1975). The MCI and QMCI were developed to indicate organic enrichment in stony bottom 103 streams and are similar to the Hilsenhoff Biotic Index (Hilsenhoff 1987).

I did not include fish in this study for two reasons: 1) In the flood prone streams of

105

106

107

108

109

\section{Periphyton}

Periphyton biomass was assessed from measures of chlorophyll $a$ taken from five stones (mean area: $60 \mathrm{~cm}^{2}$ ) at each site. These were collected randomly from riffles within the sampling reach and transported in the dark and on ice prior to being frozen. Chlorophyll $a$ was extracted by using $90 \%$ acetone at $5^{\circ} \mathrm{C}$ for $24 \mathrm{~h}$ in the dark. Absorbances were then read at 750, 665 and $664 \mathrm{~nm}$ on a Varian Cary 50 conc UV-Visible Spectrophotometer (Varian Australia Pty Ltd, Mulgrave, Australia) and converted to pigment concentration as per Steinman and Lamberti (1996). These values were then estimated and corrected for stone surface area using Graham et al. (1988) and halved to account for the fact that only half the stone surface is available for periphyton growth.

Recent studies have demonstrated the applicability of rapid assessment methods of periphyton cover (Kilroy et al., 2013; Tonkin et al., 2014a). Therefore, the percentage of periphyton cover was visually assessed and broken into four categories. These were: bare (no cover $)$, thin films $(0-1 \mathrm{~mm})$, mats $(>1 \mathrm{~mm})$ and filamentous algae. Percent bryophyte and macrophyte cover was also assessed along these transects. 
124

125

126

127

128

129

130

131

132

133

134

135

136

137

\section{Physicochemical sampling}

Physicochemical assessment was performed concurrently with biological sampling and sampled variables can be found in Table 1. Bed stability was assessed using the substrate component of the Pfankuch stability index (Pfankuch 1975), which consists of rock angularity, brightness, packing, percent stable materials, scouring and amount of clinging vegetation.

Substrate size composition was assessed using the 'Wolman Walk' method, by selecting and measuring (beta axis) 100 stones at 1-m intervals 45 degrees to the stream bank in a zigzag manner (Wolman 1954) and grouping into Wentworth scale size classes (Wentworth 1922, Cummins 1962). The percentage of these classes was then converted into a single substrate size index (SI) by summing their midpoint values weighted by their proportion (I assigned bedrock as $400 \mathrm{~mm}$ for use in the calculation) (Quinn and Hickey 1990). Stream-slope was assessed as the height drop over 10-100-m sections depending on the size of the stream. Substrate heterogeneity was calculated using the Shannon diversity index, and embededness graded on a three-point scale from loose to tight.

Conductivity, temperature and $\mathrm{pH}$ were spot-measured using a Eutech ECScan and pHtestr2 (Eutech Instruments, Singapore) respectively. Depth and current velocity were measured using a Marsh McBirney flomate current meter (Marsh McBirney, Frederick, Maryland) at five equidistant points along the thalweg, and width at three points, of each study reach.

The percentage of coarse particulate organic matter (CPOM) was visually assessed in the substrate along five transects throughout each reach. The percentage of debris jams and undercut banks were visually assessed along the entire study reach, as well as the percentage of overhead cover shading the stream. The percentage of riparian vegetation was visually assessed along each study reach broken into the following categories: native forest, native scrub, planted forest, pasture and bare ground.

Finally, catchment land-use for each site was extracted from the River Environment Classification (REC) (Snelder and Biggs 2002), and \% bare ground and \% tussock cover was combined for analyses.

\section{Data analysis}

All analyses were performed using R version 2.15.2 (R Core Team 2013). To assess the strength of the link between stream width and \% overhead cover, and whether this link was confounded by elevation, Pearson's correlation was performed using the cor.test() function. Further, to test if 
155 this link was reflected by the catchment cover of tussock and bare ground, these variables were 156 correlated with the combined tussock and bare ground percentage.

Spatial autocorrelation was examined using a Mantel test based on Pearson's productmoment correlation and 999 permutations, with the mantel() function in the package Vegan

159 (Oksanen et al. 2011). This was performed by comparing geographic with environmental and 160 macroinvertebrate dissimilarity matrices calculated using the function vegdist() in Vegan. Geographic and environmental matrices were calculated using Euclidian distances and macroinvertebrate matrices were calculated using Bray-Curtis distances on $\log (\mathrm{x}+1)$ transformed macroinvertebrate data. Geographic data was simply the NZTM (New Zealand Transverse Mercator) easting and northing coordinates. squares regression (PLSR) was performed using the plsr() function in the pls package (Mevik and Wehrens 2007). First, the environmental variables were standardised using the scale() function. PLSR was then performed using the full set of 24 standardised environmental variables and models were validated using leave-one-out cross validation. This was carried out for each of the eight macroinvertebrate metrics separately to get the best possible prediction for each individual metric and the number of components was limited to two. For the cross-validated models, the root mean square error of the estimate was calculated to evaluate the model.

For all multivariate analyses, the raw invertebrate data was $\log (\mathrm{x}+1)$ transformed to reduce heteroscedasticity. To select the best subset of environmental variables explaining variation in the multivariate macroinvertebrate community structure, BIO-ENV (Clarke and Ainsworth 1993) was performed with bioenv() in the Vegan package. This function selects the best subset of environmental variables by maximising the correlation between environmental (using Euclidean distances) and community distance matrices. Spearman rank correlations were used to correlate the matrices and Bray-Curtis distances for the community dataset.

To visually assess the multivariate structure of the macroinvertebrate community, nonmetric multidimensional scaling (nMDS) ordination was performed using the metaMDS()

182 function in the Vegan package. Again, Bray-Curtis distances were used and the number of axes 183 was limited to two. To examine the gradient of effect of the variables identified in BIO-ENV, 184 smooth surface thinplate splines were fitted using the ordisurf() function in Vegan. This 185 procedure uses generalized additive models (GAMs) to overlay a smoothed response surface, 186 which allows a more detailed interpretation than a simple linear vector. 
187

188

189

190

191

192

193

194

195

196

197

198

199

200

201

202

203

204

205

206

207

208

209

210

211

212

213

214

215

216

\section{Results}

\section{Environmental variables}

Conductivity ranged from 40 to $298 \square \mathrm{S} \mathrm{cm}^{-1}$, averaging $112.8 \square \mathrm{S} \mathrm{cm}^{-1}$ (Table 1). Spot temperature ranged from 6.6 to $17.6 \square \mathrm{C}$, with a mean of $10.79 \square \mathrm{C}$. Velocity ranged from 0.16 to $1.46 \mathrm{~m} \mathrm{~s}^{-1}$, with a mean of $0.78 \mathrm{~m} \mathrm{~s}^{-1}$ (Table 1). Mean depth was $27.19 \mathrm{~cm}$ and varied between 5.7$52.2 \mathrm{~cm}$. Substrate size varied between 43.67 and $254.64 \mathrm{~mm}$, with a mean of $143.97 \mathrm{~mm}$. Mean chlorophyll $a$ was $1.87 \square \mathrm{g} \mathrm{cm}^{-2}$ and ranged from 0.03 to $5.02 \square \mathrm{g} \mathrm{cm}^{-2}$ (Table 1). Thin films were the dominant growth form of periphyton with a mean of $46.98 \%$ cover, followed by mats with $14.26 \%$ cover (Table 1 ). Filamentous algae was rarely present with a mean of $2.51 \%$ cover. Bryophytes were highly variable ranging from 0 to $90 \%$ cover, with a mean of $13.57 \%$ cover. Environmental data were not spatially autocorrelated $(r=0.03, p=0.2)$, but there was a spatial association for the macroinvertebrate data $(r=0.08, p=0.02)$.

\section{Univariate metrics}

A total of 97 taxa was collected from the 47 sites in this study. Insects dominated all the sites and were the most taxonomically rich, with 35 caddisfly (Trichoptera) taxa, 22 Diptera, 14 mayflies (Ephemeroptera), and eight stoneflies (Plecoptera).

The pooled number of invertebrates in the benthos ranged from 15 to 5978 individuals 0.5 $\mathrm{m}^{-2}$ and the number of taxa collected at each site ranged from 4 to 45 taxa $0.5 \mathrm{~m}^{-2}$ (Table 1). MCI ranged from 90 to 134.5, averaging 113.5, and QMCI ranged between 3.07 and 7.75, averaging 5.95. Percent EPT taxa and individuals averaged approximately the same, between 55 and 59\%, but the range was much greater for \%EPT individuals (7.85-90.85) than \%EPT taxa (35.29-73.08; Table 1). There were, on average, 15 EPT taxa per site, ranging between 2 and 27 taxa.

\section{PLSR}

\section{Overall}

The first two components of the partial least squares regressions were able to explain between 41 and $70 \%$ of the variation in the eight macroinvertebrate metrics (Table 2). These components explained much less variation in the environmental data, ranging between 21 and 25\%.

14 Taxonomic richness $\left(r^{2}=0.69\right)$, EPT richness $\left(r^{2}=0.70\right)$ and Margalef's index $\left(r^{2}=0.68\right)$ were those best predicted by the environmental variables, whereas QMCI was least successfully predicted by the two components $\left(r^{2}=0.41\right.$; Table 2$)$. Component 1 variation explained ranged 
from 29\% (QMCI) to 54\% (EPT richness), with taxonomic richness $\left(r^{2}=0.49\right)$, density $\left(r^{2}=\right.$ $0.49)$ and Margalef's $\left(r^{2}=0.48\right)$ closely following. Percent overall variation explained for component 2 ranged from 10\% (\%EPT individuals) to 20\% (both taxonomic richness and Margalef's; Table 2).

\section{Key variables}

The variables with the consistently highest (or most negative) loadings on either component across all eight macroinvertebrate metrics were \% overhead cover, $\%$ bryophyte cover, $\%$ debris jam and depth (Fig. 2).

Percent overhead cover was one of the strongest predictors of the macroinvertebrate metrics (Fig. 2). Overhead cover had a loading greater than 0.4 on all of the first PLS components for all metrics except for density (richness $=0.49, \mathrm{MCI}=0.48, \mathrm{QMCI}=0.48, \% \mathrm{EPT}$ taxa $=0.52$, $\%$ EPT individuals $=0.45$, EPT richness $=0.5$, Margalef's $=0.5$; Fig. 2) and $\%$ CPOM cover contributed slightly lower positive loadings to the same component (richness $=0.36, \mathrm{MCI}=0.37$, $\mathrm{QMCI}=0.37, \% \mathrm{EPT}$ taxa $=0.38, \%$ EPT individuals $=0.35$, EPT richness $=0.35$, Margalef's $=$ 0.36; Fig. 2). On the same components that \% CPOM and overhead cover were positively loaded, width exhibited weaker negative loadings between -0.29 to -0.36 , as width and overhead cover were negatively correlated $(r=-0.45, p=0.001)$. However, overhead cover also declined with elevation $(r=-0.33, p=0.025)$, but there was no link between elevation and width $(r=-0.08, p$ $=0.58$ ). Overhead cover was highly negatively correlated with the percentage of the catchment with bare ground and tussock cover $(r=-0.73, p<0.0001)$.

Chlorophyll $a$ had the strongest loading for either component predicting macroinvertebrate density with a loading of 0.57 on component 1 and on the same component \% planted forest contributed -0.42 (Fig. 2). Percent bryophyte cover (-0.43), \% debris jam (-0.59) and \% CPOM cover (-0.43) all had strong negative loadings on the second component predicting the number of individuals (Fig. 2). As well as a strong negative loading on component 2 of the density model, debris jam contributed strong negative loadings on all of the remaining metrics (richness $=-0.42, \mathrm{MCI}=-0.32, \mathrm{QMCI}=-0.39, \% \mathrm{EPT}$ taxa $=-0.33, \% \mathrm{EPT}$ individuals $=-0.37$, EPT richness $=-0.39$, Margalef's $=-0.4$; Fig. 2). Moreover, in addition to a positive contribution by $\%$ overhead cover on component $1, \%$ periphyton mat cover contributed strongly negatively to predict QMCI (-0.43) and \%EPT individuals (-0.42; Fig. 2).

Percent bryophyte cover also contributed strongly negatively to component 2 of the MCI (-0.51), QMCI (-0.42), \%EPT taxa (-0.43) and \%EPT individuals (-0.4) models (Fig. 2). Percent 
periphyton film cover only contributed strongly to the second component of MCI (0.45) and Margalef's index (0.41). The Pfankuch stability index contributed negatively to component 1 of taxonomic richness $(-0.32)$ and density $(-0.33)$, but contributed little to any of the other models (Fig. 2).

253

254

255

256

257

258

\section{Multivariate}

The best model using BIO-ENV selected eight of the 24 environmental variables (\% overhead cover, Pfankuch, chlorophyll $a$, depth, temperature, \% debris jam, \% planted forest, \% bryophyte cover) and had a correlation (rho) of 0.562 with the multivariate community structure (Table 3 ). However, there was little improvement in the link with community structure from the model with four variables $($ rho $=0.525)$. This model included $\%$ overhead cover, Pfankuch, $\%$ planted forest and $\%$ bryophyte cover.

The nMDS ordination on $\log (\mathrm{x}+1)$ transformed macroinvertebrate communities produced a reasonable ordination with a stress of 0.159 (Fig. 3). Overlaying this ordination with individual GAM fitted smooth surfaces of each of the eight variables selected by BIO-ENV using thinplate splines indicates the main influence of these important variables was along nMDS axis 1 (Fig. 3). Sites positively loaded on axis 1, tended to be more resource rich with greater levels of chlorophyll $a$, bryophytes, overhead cover and more stable (i.e. Pfankuch).

One site (site 32), which had very low abundance (four taxa and 15 individuals collected), loaded much more negatively on axis 1 than any other site (Fig. 3). This site was situated in a plantation forestry area, which may explain the spline loadings of \% planted forest declining along this axis. At the other end of the scale, site 45, which exhibited the highest loading on nMDS 1, was a small spring-brook with a high percentage of bryophyte cover and overhead canopy cover, with a macroinvertebrate community that reflected these physical factors.

Removing this site from the nMDS increased the two-dimensional stress from 0.162 to 0.182. Furthermore, running the BIO-ENV with this site excluded reduced the link between environmental variables and the invertebrate community from rho $=0.562$ to rho $=0.533$, and the set of explanatory variables remained similar, with the notable exclusion of \% planted forest. This BIO-ENV selected nine variables: \% overhead cover, Pfankuch, chlorophyll $a$, depth, temperature, debris jam, substrate size, \% bryophyte, and \% macrophyte. Finally, excluding site 32 from the PLSR on abundance (which was the only invertebrate metric \% planted forest influenced strongly) removed the influence of planted forest on density, but also reduced the amount of variation explained by the first two components from $64 \%$ to $55 \%$. 
Splitting the invertebrate community into EPT and non-EPT taxa indicated similar

282

283

284

285

286

287

288

289

290

291

292

293

294

295

296

297

298

299

300

301

302 multivariate structure (Mantel $r=0.62, p=0.001$ ), and BIO-ENV revealed similar drivers, with 10 and 11 variables selected for each of EPT and non-EPT data respectively (Table 3).

Of the eight variables explaining multivariate structure, temperature was the only one that contributed little to univariate metric prediction. The biggest loading for temperature on any of the PLS components, was -0.21 on component 1 predicting macroinvertebrate density. The remainder of environmental variables contributed to both univariate and multivariate prediction.

\section{Discussion}

\section{Metric use}

Contrary to my hypothesis, local-scale environmental variables were able to explain substantial variation in taxonomic richness of benthic macroinvertebrate communities in these pristine mountain streams with two components of a PLSR (70\%). This is a relatively strong explanatory power for a set of streams with a highly constrained range of landscape-scale factors such as geology, climate, land-use and altitude. Nonetheless, there was considerable natural variation in environmental variables measured at these sites, which may explain the strong link with the macroinvertebrate community. In accordance with my primary hypothesis, the environmental drivers of univariate macroinvertebrate metrics and those of multivariate community structure were essentially similar. Where regional differences are present in environmental conditions, the regional species pool is an important driver of local species richness, with the ability to override local scale influences in streams (Heino et al. 2003, Tonkin et al. 2014b). However, without these regional differences, the importance shifts back to local-scale drivers, especially if large-scale factors such as geology are limited as they were in the present study.

I used a limited range of community metrics, which could potentially mask important information, given metrics both respond differently to different stressors (Yuan and Norton 2003) and only represent a small part of community dynamics. A multimetric approach may overcome this reduction of complex relationships by simultaneously explaining several aspects of community structure and increasing the likelihood of incorporating a wider range of responses to different stressors (Karr 1999). However, this approach is dependent on metrics displaying different trajectories from each other, and the metrics used here all exhibited similar responses to each other (http://dx.doi.org/10.6084/m9.figshare.1053134). Thus, a much wider range of metrics 
311

312

313

314

315

316

317

318

319

320

than used in this study would benefit a multimetric approach, such as functional diversity or taxonomic distinctness (Clarke and Warwick 1998).

Most of the variation explained in this study was by resource supply metrics, which likely reflects the fact that no anthropogenic stressors were present at these sites. The metrics used in this study are commonly applied in biomonitoring situations and have been demonstrated to respond to various anthropogenic stressors including land-use degradation, flow reduction and forest harvesting (Lenat 1988, James and Suren 2009, Reid et al. 2010, Shearer and Young 2011). Not surprisingly, given the lack of human influences that would increase nutrient or organic loads, the metrics with the weakest link with environmental drivers were those designed to respond to organic enrichments, namely MCI and QMCI.

\section{Overhead cover and resource supply metrics}

Several environmental variables strongly influenced both macroinvertebrate metrics and multivariate structure. Of these, the most important were percent overhead canopy cover, percent bryophyte cover, stream-bed stability, debris jam cover, periphyton cover and biomass, and stream size. In a previous study on these streams, Tonkin et al. (2013) showed that disturbance and productivity were important drivers in open- but not closed-canopy streams, despite canopy cover not affecting periphyton biomass. Due to a high density of cover in many New Zealand forests, canopy cover often strongly influences stream communities due to lowered periphyton standing crops (Winterbourn 1990, Death and Zimmermann 2005). However, this forest presence does not necessarily shift the functional composition due to a comparatively low level of allochthonous material entering these streams (Winterbourn et al. 1981). Canopy clearance can, however, have far-reaching consequences and can follow the subsidy-stress pattern proposed by Odum et al. (1979); where the initial response is positive before a critical threshold is reached that leads to negative effects on biodiversity of stream biota (Quinn 2000, Allan 2004). This phenomenon may be related to a greater periphyton food supply for macroinvertebrates, in the absence of shading (Death and Zimmermann 2005).

While we are dealing with pristine streams in the present study, lack of canopy is not usually an independent stressor, rather it is associated with complete shifts in land-use, which can come with much more intense pressures than simply clearing riparian vegetation (Sponseller et al. 2001). Nonetheless, Tonkin and Death (2012) found similar relationships between productivity, disturbance and diversity when comparing streams from the region assessed in this study and those of a region dominated by intensive agriculture. As expected, there was a negative 
343 link between canopy cover percentage and stream width in the present study, but this link was not

344 as strong as one would expect. I sampled a range of stream sizes, from first- to sixth-order, but

345 the only first order stream was spring-fed and the majority of second order streams had large

346 spring inputs.

347 The weakness of this canopy-width link results from several of the smaller streams

348 lacking riparian vegetation, or if present, the vegetation often consists of small shrubs and

349 tussocks, as was evident with the strong correlation between catchment bare ground and tussock

350 and overhead cover. The importance of canopy cover on these communities is, therefore, not a

351 function of an underlying stressor such as land-use change, but a natural vegetation phenomenon.

352 Riparian vegetation can structure stream communities in several ways, including provision of

353 habitat, physical structure and resource supply to stream dwellers, as well as filtering land-use

354 impacts (Naiman and Henri 1997). The importance of canopy presence in this study, therefore,

355 likely represents several other important habitat factors.

356 Along with overhead cover, bryophyte cover was an important driver of invertebrate

357 communities in both the PLSR and BIO-ENV approaches, but it did not correlate with any

358 invertebrate metric. Moss was clearly linked with stream stability and likely also reflects the flow

359 regime of these sites. Nineteen of the sites had no moss and a further 13 had 5\% cover or less,

360 therefore, it is likely a non-linear effect. Many environmental factors drive non-linear threshold

361 responses in ecological communities (Dodds et al. 2010), and while the PLSR was able to extract

362 the most important drivers of community metrics, I cannot make any inference regarding non-

363 linear effects because PLSR assumes linear relationships between the independent and dependent

364 variables.

\section{Plantation forestry}

366 The only variable to influence multivariate structure but not any of the metrics, other than

367 abundance, was the percentage of plantation forestry in the riparian zone. Yet, despite being a

368 local-scale measure, all plantation forestry sites were situated within one defined area consisting

369 of mainly mature Pinus radiata. These sites could be simply comprised of a different suite of

370 taxa, but not ultimately affect the invertebrate metrics such as taxonomic richness. However,

371 previous studies have found similar macroinvertebrate communities between sites in mature

372 Pinus radiata forestry and native forest in New Zealand streams (Quinn et al. 1997, 2004).

373 While a clear negative link with nMDS axis 1 was apparent for plantation forestry, this

374 pattern was driven largely by one site with very low abundance, and thus forestry sites did not 
group separately from the remainder of sites in ordination space. Moreover, plantation forest percentage was not related strongly to any of the other environmental variables. In fact, removing this site from the analyses removed the influence of planted forest on both community structure and abundance. Thus it may be that this single site was inflating the influence of planted forest on these communities, although, when excluded, the explanatory success of the models was reduced.

\section{Conclusions}

Overall, the drivers of community metrics and multivariate structure were largely similar. Canopy cover and resource supply metrics were the most commonly identified environmental drivers in these pristine streams. For an area with little to no anthropogenic influence, substantial variation was explained in the macroinvertebrate community, with both uni- and multivariate approaches. Given the pristine condition of these streams, this finding highlights the importance of considering natural underlying environmental variation when assessing biodiversity against coarser gradients of environmental change. The strength of this link also highlights the considerable range of environmental conditions present in these pristine streams shaping the macroinvertebrate communities present. Despite most metrics performing in a similar manner, I suggest it is important to use a wide range of metrics and approaches to represent the entire macroinvertebrate community. Moreover, given the importance of canopy cover presence in driving these communities, as well as its potential to mask the effects of anthropogenic stressors, it is crucial to account for this variable, and further research its role, in bioassessment programs.

\section{Acknowledgements}

I thank Roger Tonkin, Amber McEwan, Nicki Atkinson, Manas Chakraborty, Robert Charles, Logan Brown, and Alana Lawrence for help with fieldwork. Keith Wood at Ernslaw One Limited provided access to Karioi Forest sites. Department of Conservation allowed access to conservation areas. Kevin Collier, Esta Chappell, Svein Saltveit and two anonymous reviewers provided valuable comments on the manuscript.

\section{References}

Allan, J. D. 2004. Landscapes and riverscapes: the influence of land use on stream ecosystems. Annual Review of Ecological and Evolutionary Systematics 35:257-284. 
403

404

405

406

407

408

409

410

411

412

413

Astorga, A., J. Heino, M. Luoto, and T. Muotka. 2011. Freshwater biodiversity at regional extent: determinants of macroinvertebrate taxonomic richness in headwater streams. Ecography 34:705-713.

Clarke, K. R., and M. Ainsworth. 1993. A Method of Linking Multivariate Community Structure to Environmental Variables. Marine Ecology-Progress Series 92:205-219.

Clarke, K. R., and R. M. Warwick. 1998. A taxonomic distinctness index and its statistical properties. Journal of Applied Ecology 35:523-531.

Clarke, R. T., J. F. Wright, and M. T. Furse. 2003. RIVPACS models for predicting the expected macroinvertebrate fauna and assessing the ecological quality of rivers. Ecological Modelling 160:2119-2233.

Clifford, H. T., and W. Stephenson. 1975. An Introduction to Numerical Classification. Academic Press.

Collier, K. J. 2009. Linking multimetric and multivariate approaches to assess the ecological condition of streams. Environmental monitoring and assessment 157:113-24.

Cummins, K. W. 1962. An evaluation of some techniques for the collection and analysis of benthic samples with special emphasis on lotic waters. American Midland Naturalist 67:477-504.

Death, R. G., and K. J. Collier. 2010. Measuring stream macroinvertebrate responses to gradients of vegetation cover: when is enough enough? Freshwater Biology 55:1447-1464.

Death, R. G., and M. K. Joy. 2004. Invertebrate community structure in streams of the Manawatu-Wanganui region, New Zealand: the roles of catchment versus reach scale influences. Freshwater Biology 49:982-997.

Death, R. G., and M. J. Winterbourn. 1995. Diversity patterns in stream benthic invertebrate communities: the influence of habitat stability. Ecology 76:1446-1460.

Death, R. G., and E. M. Zimmermann. 2005. Interaction between disturbance and primary productivity in determining stream invertebrate diversity. Oikos 111:392-402.

Dodds, W. K., W. H. Clements, K. Gido, R. H. Hilderbrand, and R. S. King. 2010. Thresholds, breakpoints, and nonlinearity in freshwaters as related to management. Journal of the North American Benthological Society 29:988-997.

Fuller, R. L., C. LaFave, M. Anastasi, J. Molina, H. Salcedo, and S. Ward. 2008. The role of canopy cover on the recovery of periphyton and macroinvertebrate communities after a month-long flood. Hydrobiologia 598:47-57. 
435 Graham, A. A., D. J. McCaughan, and F. S. McKee. 1988. Measurement of surface area of stones. 436 Hydrobiologia 157:85-87.

437 Harding, J. S., E. F. Benfield, P. V Bolstad, and E. B. D. Jones III. 1998. Stream biodiversity: The 438 ghost of land use past. Proceedings of the National Academy of Sciences 95:14843-14847.

439 Hawkins, C. P., R. H. Norris, J. Gerritsen, R. M. Hughes, S. K. Jackson, R. K. Johnson, and R. J. 440 Stevenson. 2000. Evaluation of the use of landscape classifications for the prediction of 441 freshwater biota: synthesis and recommendations. Journal of the North American $442 \quad$ Benthological Society 19:541-556.

443 Heino, J. 2009. Biodiversity of aquatic insects: spatial gradients and environmental correlates of 444 assemblage-level measures at large scales. Freshwater Reviews 2:1-29.

445 Heino, J., T. Muotka, and R. Paavola. 2003. Determinants of macroinvertebrate diversity in 446 headwater streams: regional and local influences. Journal of Animal Ecology 72:425-434. 447 Heino, J., H. Mykrä, and J. Kotanen. 2008. Weak relationships between landscape characteristics 448 and multiple facets of stream macroinvertebrate biodiversity in a boreal drainage basin. $449 \quad$ Landscape Ecology 23:417-426.

450 Hilsenhoff, W. L. 1987. An improved biotic index of organic stream pollution. Great Lakes $451 \quad$ Entomologist 20:31-41.

452 Jacobsen, D., R. Schultz, and A. Encalada. 1997. Structure and diversity of stream invertebrate 453 assemblages: the influence of temperature with altitude and latitude. Freshwater Biology $454 \quad 38: 247-261$.

455 James, A. B. W., and A. M. Suren. 2009. The response of invertebrates to a gradient of flow 456 reduction - an instream channel study in a New Zealand lowland river. Freshwater Biology $457 \quad 54: 2225-2242$.

458 Johnson, L., and S. Gage. 1997. Landscape approaches to the analysis of aquatic ecosystems. $459 \quad$ Freshwater Biology 37:113-132.

460 Johnson, L., C. Richards, G. Host, and J. Arthur. 1997. Landscape influences on water chemistry 461 in Midwestern stream ecosystems. Freshwater Biology 37:193-208.

462 Karr, J. R. 1999. Defining and measuring river health. Freshwater Biology 41:221-234.

463 Kerans, B. L., and J. R. Karr. 1994. A benthic index of biotic integrity (B-IBI) for rivers of the 464 Tennessee Valley. Ecological Applications 4:768-785. 
Kilroy, C., D. Booker, L. Drummond, J. Wech, and T. Snelder. 2013. Estimating periphyton standing crop in streams: a comparison of chlorophyll $a$ sampling and visual assessments. New Zealand Journal of Marine and Freshwater Research 47:208-224.

Lenat, D. R. 1988. Water quality assessment of streams using a qualitative collection method for benthic invertebrates. Journal of the North American Benthological Society 7:222-233.

Magurran, A. E. 2004. Measuring Biological Diversity. Page 256. Blackwell Science Ltd, Oxford, UK.

Mevik, B., and R. Wehrens. 2007. The pls package: principal component and partial least squares regression in R. Journal of Statistical Software 18:1-24.

Naiman, R. J., and D. Henri. 1997. The ecology of interfaces: riparian zones. Annual Review of Ecology and Systematics 28:621-658.

Odum, E. P., J. T. Finn, and E. H. Franz. 1979. Perturbation-theory and the subsidy-stress gradient. Bioscience 29:349-352.

Oksanen, J., F. G. Blanchet, R. Kindt, P. Legendre, P. R. Minchin, R. B. O’Hara, G. L. Simpson, P. Solymos, M. Henry, H. Stevens, and H. Wagner. 2011. Vegan: Community Ecology Package. R package version 2.0-1.

Pfankuch, D. 1975. Stream Reach Inventory and Channel Stability Evaluation. USDA Forest Service, Region 1, Missoula, Montana.

Poff, N. L. 1997. Landscape filters and species traits: Towards mechanistic understanding and prediction in stream ecology. Journal of the North American Benthological Society 16:391409.

Quinn, J. M. 2000. Effects of pastoral development. Pages 208-229 in K. J. Collier and M. J. Winterbourn, editors. New Zealand stream invertebrates: ecology and implications for management. The Caxton Press, Christchurch, New Zealand.

Quinn, J. M., I. K. . Boothroyd, and B. J. Smith. 2004. Riparian buffers mitigate effects of pine plantation logging on New Zealand streams. Forest Ecology and Management 191:129-146.

Quinn, J. M., A. B. Cooper, R. J. Davies-Colley, J. C. Rutherford, and R. B. Williamson. 1997. Land use effects on habitat, water quality, periphyton and benthic invertebrates in Waikato, New Zealand, hill-country streams. New Zealand Journal of Marine and Freshwater Research 31:579-597. 
495

496

Quinn, J. M., and C. W. Hickey. 1990. Characterisation and classification of benthic invertebrate communities in $88 \mathrm{New}$ Zealand rivers in relation to environmental factors. New Zealand Journal of Marine and Freshwater Research 24:387-409.

R Core Team. 2013. R: A language and environment for statistical computing. R Foundation of Statistical Computing, Vienna, Austria.

Reid, D. J., J. M. Quinn, and A. E. Wright-Stow. 2010. Responses of stream macroinvertebrate communities to progressive forest harvesting: Influences of harvest intensity, stream size and riparian buffers. Forest Ecology and Management 260:1804-1815.

Reynoldson, T. B., R. H. Norris, V. H. Resh, K. E. Day, and D. M. Rosenberg. 1997. The reference condition: a comparison of multimetric and multivariate approaches to assess water-quality impairment using benthic macroinvertebrates. Journal of the North American Benthological Society 16:833-852.

Shearer, K., and R. Young. 2011. Influences of geology and land use on macroinvertebrate communities across the Motueka River catchment, New Zealand. New Zealand Journal of Marine and Freshwater Research 45:437-454.

Smith, M. J., W. R. Kay, D. H. D. Edward, P. J. Papas, K. S. T. J. Richardson, J. C. Simpson, A. M. Pinder, D. J. Cale, P. H. J. Horwitz, J. A. Davis, F. H. Yung, R. H. Norris, and S. A. Halse. 1999. AusRivAS: using macroinvertebrates to assess ecological condition of rivers in Western Australia. Freshwater Biology 41:269-282.

Snelder, T. H., and B. J. F. Biggs. 2002. Multiscale river environment classification for water resources management. Journal of the American Water Resources Association 38:12251239.

Sponseller, R., E. Benfield, and H. Valett. 2001. Relationships between land use, spatial scale and stream macroinvertebrate communities. Freshwater Biology 46:1409-1424.

Stark, J. D. 1985. A macroinvertebrate community index of water quality for stony streams. Water \& Soil miscellaneous publication 87:53 p.

Stark, J. D. 1993. Performance of the Macroinvertebrate Community Index: effects of sampling method, sample replication, water depth, current velocity, and substratum on index values. New Zealand Journal of Marine and Freshwater Research 27:463-478.

Steinman, A. D., and G. A. Lamberti. 1996. Biomass and pigments of benthic algae. Pages 295314 in F. R. Hauer and G. A. Lamberti, editors. Methods in Stream Ecology. Academic Press, San Diego, CA. 
527 Tonkin, J. D., and R. G. Death. 2012. Consistent effects of productivity and disturbance on 528 diversity between landscapes. Ecosphere 3:art108.

529 Tonkin, J. D., R. G. Death, and K. J. Collier. 2013. Do productivity and disturbance interact to 530 modulate macroinvertebrate diversity in streams? Hydrobiologia 701:159-172.

531 Tonkin, J. D., R. G. Death, and J. Barquin. 2014a. Periphyton control on stream invertebrate 532 diversity: is periphyton architecture more important than biomass? Marine and Freshwater $533 \quad$ Research doi:10.1071/MF13271.

534 Tonkin, J. D., S. Stoll, A. Sundermann, and P. Haase. 2014b. Dispersal distance and the pool of 535 taxa, but not barriers, determine the colonisation of restored river reaches by benthic $536 \quad$ invertebrates. Freshwater Biology doi:10.1111/fwb.12387.

537 Towns, D. R., and W. L. Peters. 1996. Leptophlebiidae (Insecta: Ephemeroptera). (C. T. Duval, 538 Ed.) Fauna of New Zealand. Manaaki Whenua Press, Lincoln, New Zealand.

539 Vinson, M. R., and C. P. Hawkins. 1998. Biodiversity of stream insects: variation at local, basin, $540 \quad$ and regional scales. Annual Review of Entomology 43:271-293.

541 Wentworth, C. K. 1922. A scale of grade and class terms for clastic sediments. The Journal of 542 Geology:377-392.

543 Winterbourn, M. J. 1990. Interactions among nutrients, algae and invertebrates in a New Zealand 544 mountain stream. Freshwater Biology 23:463-474.

545 Winterbourn, M. J., K. L. D. Gregson, and C. H. Dolphin. 2000. Guide to the aquatic insects of $546 \quad$ New Zealand. Entomological Society of New Zealand, Auckland.

547 Winterbourn, M. J., J. S. Rounick, and B. Cowie. 1981. Are New Zealand stream ecosystems 548 really different? New Zealand Journal of Marine and Freshwater Research 15:321-328.

549 Wolman, M. J. 1954. A method of sampling coarse river bed material. Transactions of the $550 \quad$ American Geophysical Union 35:951-956.

551 Yuan, L., and S. Norton. 2003. Comparing responses of macroinvertebrate metrics to increasing 552 stress. Journal of the North American Benthological Society 22:308-322. 


\section{Table 1 (on next page)}

Summary statistics of macroinvertebrate metrics and environmental variables

Summary statistics of the eight macroinvertebrate metrics and 24 environmental variables sampled from 47 streams in the Tongariro National Park, New Zealand, 2007. $\mathrm{MCl}=$ Macroinvertebrate Community Index, $\mathrm{QMCl}=$ Quantitative $\mathrm{MCI}, \% \mathrm{EPT}=\%$ Ephemeroptera, Plecoptera and Trichoptera. 


\begin{tabular}{|l|l|l|l|l|}
\hline Variable & Min. & Max & Mean & S.E. \\
\hline Richness & 4.00 & 45.00 & 27.28 & 1.17 \\
\hline Number of individuals & 15.00 & 5978.00 & 1486.30 & 168.06 \\
\hline MCI & 90.00 & 134.50 & 113.50 & 1.48 \\
\hline QMCI & 3.07 & 7.75 & 5.95 & 0.18 \\
\hline \%EPT taxa & 35.29 & 73.08 & 54.75 & 1.17 \\
\hline \%EPT individuals & 7.85 & 90.85 & 58.83 & 3.52 \\
\hline EPT richness & 2.00 & 27.00 & 15.19 & 0.80 \\
\hline Margalef's & 0.99 & 6.08 & 3.72 & 0.15 \\
\hline Chlorophyll $a\left(\mu \mathrm{cm}^{-2}\right)$ & 0.03 & 5.02 & 1.87 & 0.19 \\
\hline Conductivity $\left(\mu \mathrm{S} \mathrm{cm}{ }^{-1}\right)$ & 40.00 & 298.00 & 112.80 & 8.54 \\
\hline Depth $\left(\mathrm{cm}^{-}\right)$ & 5.70 & 52.20 & 27.19 & 1.61 \\
\hline Embededness & 1.00 & 3.00 & 2.06 & 0.10 \\
\hline Pfankuch & 14.00 & 55.00 & 33.55 & 1.66 \\
\hline pH & 6.70 & 8.70 & 7.95 & 0.07 \\
\hline Slope $\left(\mathrm{m} 10 \mathrm{~m}^{-1}\right)$ & 1.04 & 12.80 & 4.30 & 0.31 \\
\hline Substrate heterogeneity & 1.44 & 2.30 & 1.92 & 0.03 \\
\hline Substrate size index & 43.67 & 254.64 & 143.97 & 7.20 \\
\hline Temperature $\left({ }^{\circ} \mathrm{C}\right)$ & 6.60 & 17.60 & 10.79 & 0.31 \\
\hline Velocity $\left(\mathrm{m} \mathrm{s}{ }^{-1}\right)$ & 0.16 & 1.46 & 0.78 & 0.05 \\
\hline Width $(\mathrm{m})$ & 1.43 & 30.00 & 9.35 & 1.23 \\
\hline \% Bryophyte cover & 0.00 & 90.00 & 13.57 & 3.53 \\
\hline \% CPOM cover & 0.00 & 60.00 & 7.36 & 1.67 \\
\hline \% Debris jam & 0.00 & 60.00 & 3.13 & 1.36 \\
\hline \% Filamentous cover & 0.00 & 28.00 & 2.51 & 0.69 \\
\hline \% Film cover & 0.00 & 90.00 & 46.98 & 4.22 \\
\hline \% Macrophyte cover & 0.00 & 20.00 & 0.43 & 0.43 \\
\hline \% Mat cover & 0.00 & 85.00 & 14.26 & 3.51 \\
\hline \% Native forest & 0.00 & 100.00 & 39.15 & 5.72 \\
\hline \% Native scrub & 0.00 & 100.00 & 54.26 & 5.35 \\
\hline \% Overhead cover & 0.00 & 90.00 & 31.64 & 4.65 \\
\hline \% Planted forest & 0.00 & 80.00 & 6.38 & 2.61 \\
\hline \% Undercut & 0.00 & 40.00 & 3.28 & 1.01 \\
\hline & & & & \\
\hline & & & & \\
\hline
\end{tabular}




\section{Table 2 (on next page)}

Partial least squares regression summary statistics

Results of partial least squares regression (PLSR) for each of the eight macroinvertebrate metrics collected from 47 streams in the Tongariro National Park, 2007. The first two columns are the results using leave-one-out cross validation and the remaining columns are those using the full set of data. RMSE = root mean square error of estimate. $\mathrm{MCI}=$ Macroinvertebrate Community Index, $\mathrm{QMCI}=$ Quantitative $\mathrm{MCI}, \% \mathrm{EPT}=\%$ Ephemeroptera, Plecoptera and Trichoptera. 


\begin{tabular}{|l|r|r|r|r|r|r|}
\hline & \multicolumn{3}{|c|}{ Cross validated } & \multicolumn{4}{c|}{ Training dataset } \\
\hline Metric & \multicolumn{2}{|c|}{ RMSE } & \multicolumn{1}{c|}{$\boldsymbol{r}^{2}$ environmental variables } & $\boldsymbol{r}^{2}$ macroinvertebrate metrics \\
\hline Metric & Comp 1 & \multicolumn{1}{|c|}{ Comp 2 } & \multicolumn{1}{c|}{ Comp 1 } & \multicolumn{1}{c|}{ Comp 2 } & \multicolumn{1}{l|}{ Comp 1 } & Comp 2 \\
\hline Richness & 6.945 & 6.241 & 14.84 & 23.93 & 49.06 & 69.18 \\
\hline $\log$ (abundance) & 0.4291 & 0.4221 & 9.993 & 21.1 & 49.153 & 64.12 \\
\hline MCI & 9.005 & 9.771 & 16.7 & 24.81 & 42 & 52.01 \\
\hline QMCI & 1.26 & 1.351 & 13.7 & 24.49 & 29.27 & 40.64 \\
\hline \% EPT taxa & 7.541 & 7.753 & 14.57 & 24.69 & 40.65 & 52.04 \\
\hline \% EPT individuals & 23.36 & 24.09 & 12.47 & 24.65 & 38.21 & 47.96 \\
\hline EPT richness & 4.512 & 4.071 & 14.99 & 24.46 & 53.55 & 70.38 \\
\hline Margalef's index & 0.9097 & 0.837 & 15.41 & 23.9 & 48.13 & 68.29 \\
\hline
\end{tabular}




\section{Table 3 (on next page)}

BIO-ENV correlating environmental data and macroinvertebrate community structure

The best subset of variables selected using BIO-ENV correlating multivariate community structure with (a) all, (b) EPT only and (c) non-EPT taxa collected from 47 streams in the Tongariro National Park, 2007. 


\begin{tabular}{|l|l|l|l|l|l|}
\hline \multicolumn{2}{|c|}{ All } & \multicolumn{2}{c|}{ EPT } & \multicolumn{2}{c|}{ Non-EPT } \\
\hline Variable & Spearman rho & Variable & $\begin{array}{l}\text { Spearman } \\
\text { rho }\end{array}$ & Variable & \\
\hline Bryophyte & 0.375 & Bryophyte & 0.426 & Pfankuch & 0.227 \\
\hline + Planted forest & 0.442 & + Planted forest & 0.483 & + Overhead cover & 0.323 \\
\hline + Pfankuch & 0.480 & + Macrophyte & 0.496 & + Bryophyte & 0.368 \\
\hline + Overhead cover & 0.525 & + Depth & 0.518 & + Debris jam & 0.418 \\
\hline + Debris jam & 0.536 & + Planted forest & 0.546 & + Temperature & 0.430 \\
\hline + Temperature & 0.548 & + Debris jam & 0.555 & + Slope & 0.442 \\
\hline + Chlorophyll $a$ & 0.554 & + Temperature & 0.564 & + Conductivity & 0.453 \\
\hline + Depth & 0.562 & + Pfankuch & 0.578 & + Embededness & 0.463 \\
\hline & & + Chlorophyll $a$ & 0.584 & + Native scrub & 0.468 \\
\hline & & + Overhead cover & 0.586 & + \% Films & 0.468 \\
\hline & & & & + Pfankuch & 0.468 \\
\hline
\end{tabular}




\section{Figure 1}

Map of 47 study sites

Location of the 47 study sites in the Tongariro National Park, New Zealand. Plate on right is colour coded from light to dark based on increasing stream order to indicate the number of major drainages that were sampled. Pfank. btm = bottom component of the Pfankuch stability index.

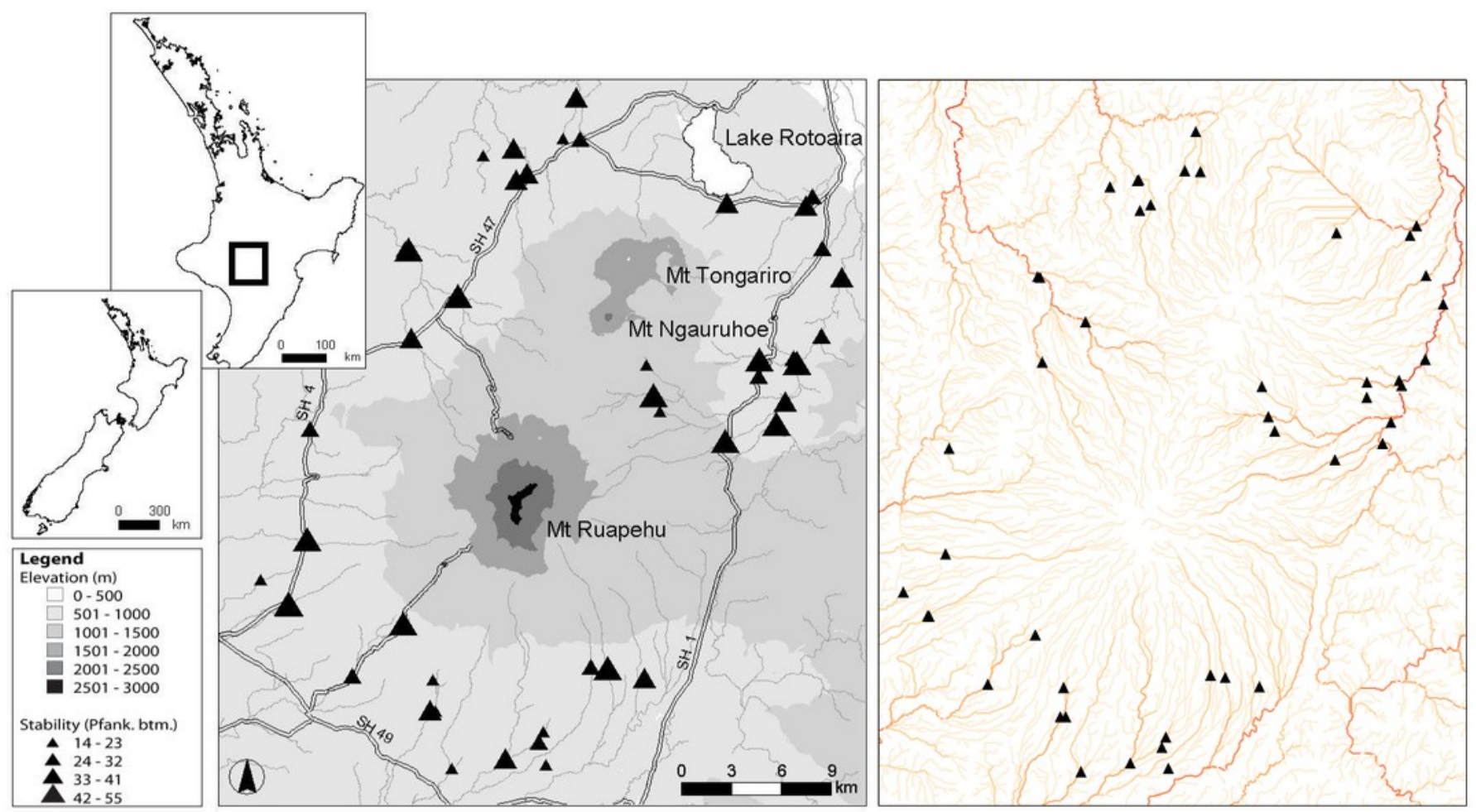




\section{Figure 2}

Loadings of environmental variables on partial least squared regression models

Loadings plot the contribution of 24 environmental variables to the first two components of eight partial least squares regression (PLSR) models. Individual PLSR models were calculated for the eight macroinvertebrate metrics collected from 47 Tongariro National Park, New Zealand streams between February and April 2007. $\mathrm{S}=$ taxonomic richness, $\mathrm{N}=$ number of individuals, $\mathrm{MCl}=$ Macroinvertebrate Community Index, $\mathrm{QMCl}=$ Quantitative $\mathrm{MCl}$, $\%$ EPT T = \% Ephemeroptera, Plecoptera and Trichoptera taxa, \% EPT I = \% EPT individuals, EPT R = EPT richness. Numbers represent PLSR component number. Chl. $a=$ chlorophyll a, Deb. jam = debris jam, OH Cover = overhead cover, SI = substrate size index, Sub. het. = substrate heterogeneity. 


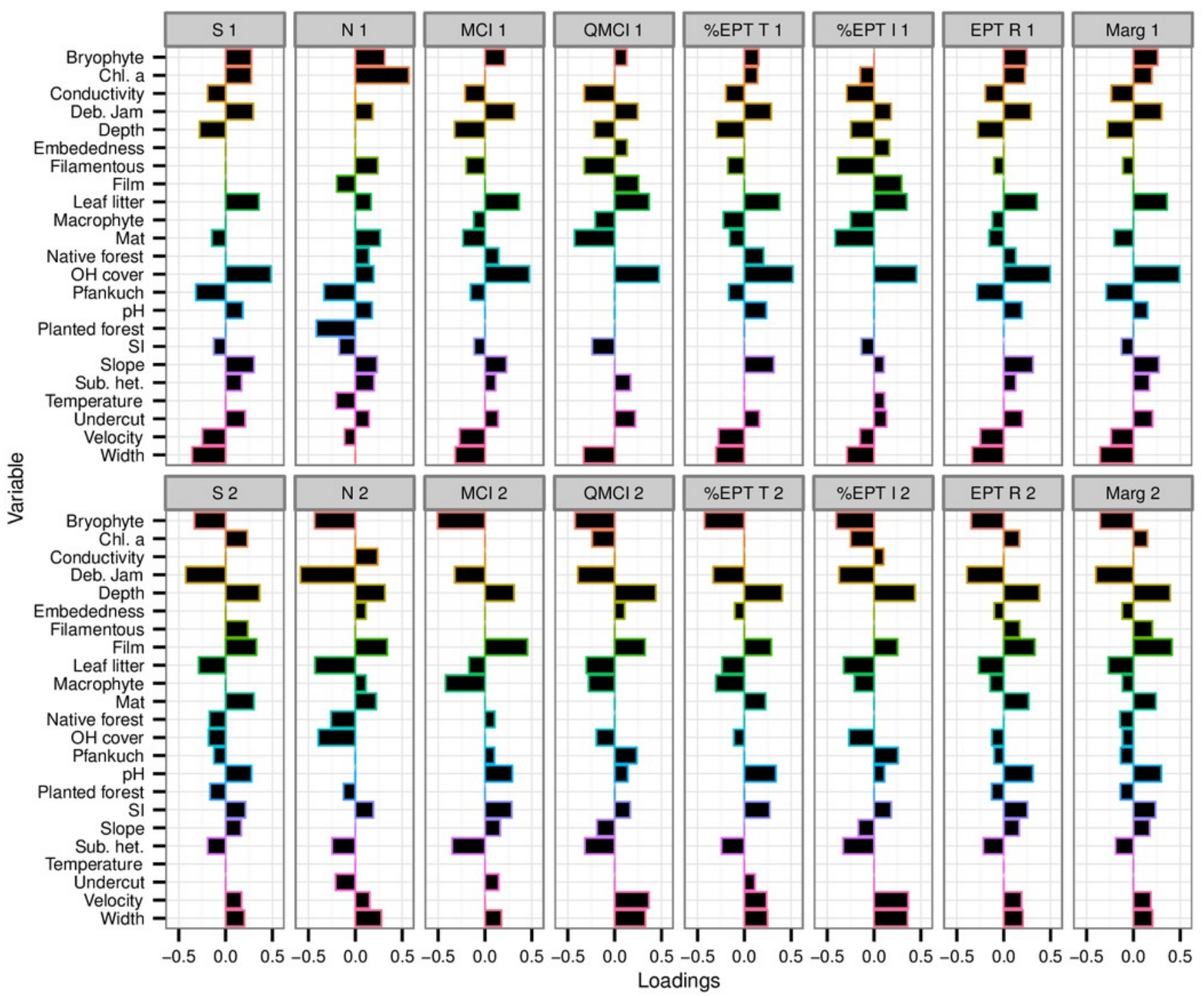




\section{Figure 3}

nMDS ordinations on macroinvertebrate communities of 47 study sites

Biplots of the non-metric multidimensional scaling ordination on $\log (x+1)$ transformed macroinvertebrate community data collected from 47 streams in the Tongariro National Park, New Zealand, 2007. Individual plots display overlaid smooth surface thinplate splines using generalized additive models (GAMs) for the eight environmental variables selected using BIO-ENV. Numbers on the splines represent value of the specific environmental variable. $\mathrm{OH}$ Cover $=$ overhead cover, Chl. $\mathrm{a}=$ chlorophyll $a$. 

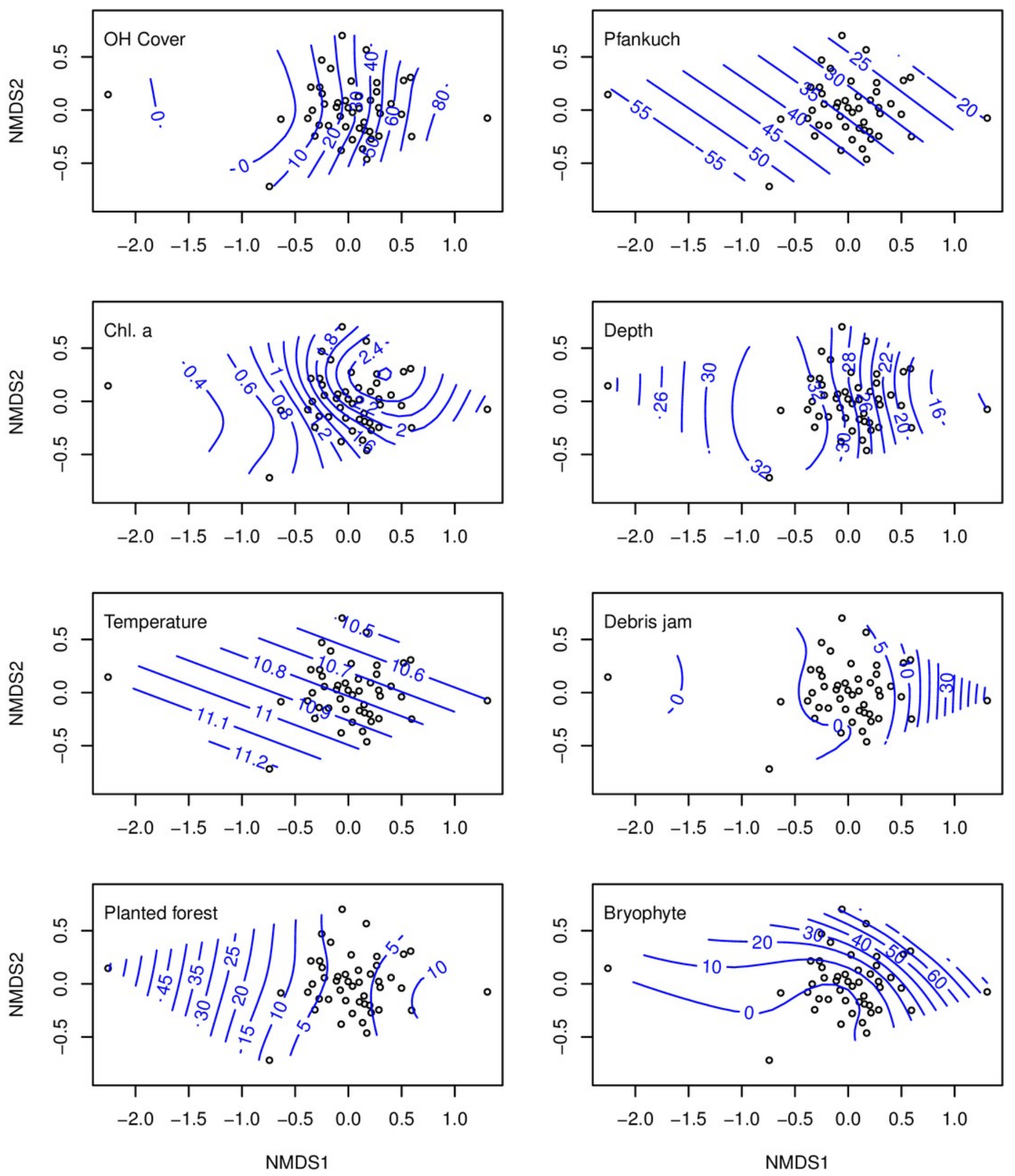